\title{
PROGRAMA DE APOIO E EDUCAÇÃO EM SAÚDE AMBIENTAL NO ESTADO DO AMAPÁ: A BUSCA POR UMA EDUCAÇÃO AMBIENTAL QUE CONTRIBUA PARA A CONSTRUÇÃO DE UMA SOCIEDADE AMBIENTALMENTE SAUDÁVEL E SUSTENTÁVEL
}

\author{
Fabiana Cunha Leão \\ Pompermayer \\ fabiana.educato@gmail.com \\ Universidade Federal do Rio de \\ Janeiro - UFRJ, Rio de Janeiro, Rio \\ de Janeiro, Brasil.
}

Jefferson Ribeiro Fernandes Jefferson.ribeiro.fernandes@gmail. com

Universidade Federal Fluminense UFF, Niterói, Rio de Janeiro, Brasil.

\section{Maria Herminia Shenkel}

maria_herminia@hotmail.com Universidade Federal Fluminense UFF, Niterói, Rio de Janeiro, Brasil.

\section{Silene Lima Dourado Ximenes} Santos

silenexfunasa@gmail.com

Fundação Nacional da Saúde FUNASA, Brasília, Distrito Federal, Brasil.

\section{Marcelo Pompermayer de} Almeida

marcelo@valorainova.com.br Universidade Federal Fluminense UFF, Niterói, Rio de Janeiro, Brasil.

\section{Estefan Monteiro Fonseca}

oceano25@hotmail.com Universidade Federal Fluminense UFF, Niterói, Rio de Janeiro, Brasil.

\begin{abstract}
RESUMO
A sustentabilidade ambiental é um dos temas mais abordados na atualidade e seus conceitos, sem dúvida, devem ocupar as pautas educacionais. Sua aplicação na educação se mostra de grande importância, uma vez que, a mudança de atitudes referentes ao meio ambiente deve ser proporcionada através das mudanças culturais. Com base nestes preceitos, Universidade Federal Fluminense (UFF) com o apoio da Fundação Nacional de Saúde (FUNASA) executou o Programa de Apoio e Educação em Saúde Ambiental (PAESA). Este programa consistiu na execução de estudos estratégicos voltados à saúde ambiental nas instituições de ensino do Estado do Amapá e atendimento aos povos e às comunidades tradicionais, referente à qualidade da água e seu impacto na saúde da população local. O presente artigo apresenta as dificuldades enfrentadas e aprendizados obtidos através deste projeto abordando os possíveis alcances da sinergia entre a educação infantil e a educação ambiental, buscando um encontro das abordagens teóricas com a prática educativa. Isso foi a grande aposta do PAESA: começar a disseminar a importância de tornar os integrantes das comunidades (escolas etc.) um agente participante na busca por caminhos e estratégias que modifiquem as realidades locais.
\end{abstract}

Palavras-chave: Saúde Ambiental, Educação Ambiental, Saneamento Ambiental 


\section{INTRODUÇÃO}

Ao longo da década de 1980, a Organização Mundial da Saúde (OMS), motivada a intensificar o controle da morbidade causada por várias doenças parasitárias, iniciou-se uma nova fase de promoção de programas de saúde ambiental, baseados na participação popular, cuja ferramenta principal foi e continua sendo a educação (WHO, 1985). Fica claro o papel da educação na geração e divulgação de conceitos para o exercício pleno da cidadania e participação popular (Mello, 1975). Por outro lado, o acesso à educação, principalmente em países menos desenvolvidos, é uma questão política, sendo este um dos principais obstáculos para o seu pleno desenvolvimento (Schall, 1994). Neste contexto, o papel da universidade se apresenta como conciliador dos diversos atores atuantes neste processo (Baptista Neto et al., 2020).

Há algum tempo, o modelo de educação tradicional não considerava a realidade das comunidades e muito menos sua qualidade de saúde (Carvalho, 1978). Atualmente, verifica-se uma evolução deste modelo, pretendendo-se promover padrões de higiene através da abordagem de procedimentos básicos com os mais jovens, a aplicação de métodos e materiais de limpeza, além de uma alimentação adequada. O novo modelo estabelece uma relação de causa e efeito com a questão da existência de enfermidades, seja pela ausência de atitudes preventivas ou pelo reconhecimento dos sinais iniciais de adoecimento e conscientização das opções de tratamento (Tatochenco, 1979).

O incremento da capacidade intelectual das castas mais pobres da sociedade tem exposto a inefetividade do modelo tradicional de educação. Isto é resultante, principalmente, de interesses políticos distintos das próprias populações. Nesta concepção, a atuação educacional utiliza-se de um modelo ultrapassado baseado em conceitos técnicos transmitidos verticalmente e que não considera valorável a historicidade das práticas e dos conteúdos educacionais.

Ao contrário, na atualidade, sabe-se que a educação em saúde para ser efetiva deve se basear principalmente na valorização da sabedoria local e no reconhecimento das práticas populares no enfrentamento dos problemas, necessitando de uma adequação e atualização constantes das informações técnico-científicas em desenvolvimento, na manutenção constante do foco na promoção da saúde e na melhoria da qualidade de vida (Júnio; Barbosa, 2017). Neste sentido, é de extrema importância que os educadores promovam a educação participativa onde o saber técnico e a sabedoria popular se complementam. Os conteúdos não são exclusivos do educador, evoluindo da prática: "o saber nasce e se desenvolve à medida que as pessoas refletem sobre as experiências vividas em todas as práticas" (Freire, 1979). A aplicação do conceito de saúde e doença no ensino resulta, assim, no questionamento sobre as várias dimensões que envolvem esses conceitos, e sobre a sua natureza complexa e multifacetada (Schall, 1994).

A proposta do presente artigo é compartilhar informações sobre o aprendizado enriquecedor obtido no estado do Amapá com o Programa de Apoio e Educação em Saúde Ambiental (PAESA), desenvolvido pela Universidade Federal Fluminense (UFF) em cooperação com a Fundação Nacional de Saúde (FUNASA). O programa foi desenvolvido para a execução de estudos estratégicos nas entidades de ensino do Amapá referentes à qualidade da água como subsídios para a aplicação de educação ambiental em benefício da saúde coletiva. Os estudos estratégicos foram desenvolvidos para refletir a gestão socioambiental nas entidades públicas de ensino no Amapá; realizar avaliação e diagnóstico socioambiental e avaliação físico-química de ambientes potencialmente contaminados; criar e aplicar métodos de educação ambiental tanto no eixo formal de educação como em povos e comunidades tradicionais (PCT).

\section{MATERIAIS E MÉTODOS}

A UFF estabeleceu equipes técnicas para o PAESA que percorreram 14 municípios do Amapá. Os municípios selecionados para as ações do programa foram os que pertencem ao escopo de atuação da FUNASA, ou seja, que possuem menos de 50.000 habitantes. Os municípios acompanhados pelo PAESA foram: Amapá, Calçoene, Cutias, Ferreira Gomes, Itaubal, Laranjal do Jari, Mazagão, Oiapoque, Pedra Branca do Amapari, Porto Grande, Pracuúba, Serra do Navio, Tartarugalzinho e Vitória do Jari (Figura 1). De agosto de 2018 a dezembro de 2019 foram desenvolvidas ações junto às escolas públicas municipais e estaduais do Amapá e PCT. Foram atendidas escolas urbanas e rurais.

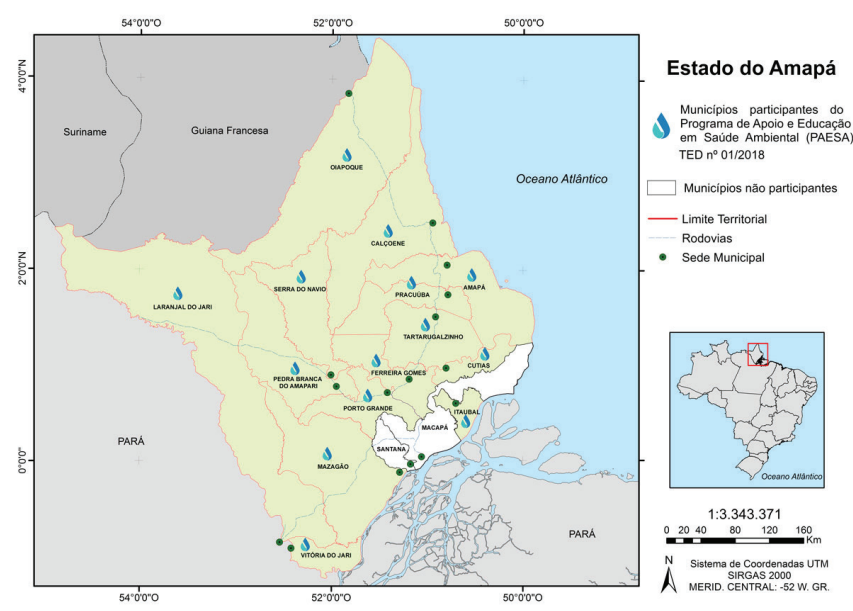

Figura 1. Área de Estudos 
A proposta do programa PAESA foi desenvolver duas frentes de atuação: uma para a efetivação de diagnóstico da qualidade da água nas escolas públicas amapaenses e outra de aplicação de metodologias de educação ambiental. As ações de educação ambiental foram realizadas considerando três eixos: educação formal (docentes e discentes), educação à distância com a construção de uma plataforma online denominada Comunidade de Aprendizagem em Saúde Ambiental (CASA) e PCT. A experiência do PAESA junto à comunidade amapaense consolidou-se de forma produtiva, tanto pela possibilidade de levar informação sobre qualidade da água e saúde ambiental para a população, como pelo impacto da vivência de campo que nos impulsionou a refletir sobre a educação ambiental no país como um paradigma a ser modificado, ou pelo menos ampliado. $\mathrm{O}$ contato com docentes e discentes de escolas urbanas e rurais, $\mathrm{PCT}$ e população ribeirinha nos levou a uma profunda reflexão do que vem a ser de fato educação ambiental, além de saber qual a sua eficácia.

Por essa razão, desenvolvemos este artigo tanto para compartilhar a experiência do programa como para propor e iniciar uma discussão sobre a temática da educação ambiental, do quanto ela tem sido (in)eficaz no país para a construção de uma sociedade ambientalmente saudável e sustentável. Talvez, assim, possamos desenvolver mais projetos que vá a campo ouvir a voz de quem vive a problemática das catástrofes ambientais que assolam um país com mínimas condições de saneamento básico, ao invés de criar teorias e metodologias de educação ambiental dentro dos muros acadêmicos.

A proposta de ações de educação ambiental do PAESA foi dividida em três eixos de atuação: educação ambiental formal, que se ocupou de atividades para docentes e discentes de escolas públicas; o programa CASA, criação e desenvolvimento de um espaço virtual de aprendizagem continuada para professores; e PCT, que se ocupou de atividades para as comunidades tradicionais de cada município atendido pelo programa.

\section{Educação Ambiental “Eixo Formal”}

As ações de educação ambiental do PAESA, que contemplaram os 14 municípios do estado do Amapá, foram divididas em três campanhas. Na oportunidade de cada campanha, ações específicas foram realizadas na modelagem de oficinas de educação ambiental, tendo como público-alvo os docentes e discentes das redes municipais de ensino fundamental e escolas estaduais de ensino médio. Uma etapa de cada oficina realizada propôs atividades de educação ambiental realizadas de modo a emancipar, conscientizar e exercer a cidadania, sempre respeitando as singularidades, culturas e histórias dos participantes. Cada participante foi estimulado a construir seu conhecimento com suas expe- riências e a desenvolver uma responsabilidade crítica, de modo que possam ser capazes de resolver e entender os problemas ambientais que vivenciam.

Na primeira campanha realizada de modo presencial no município, foram utilizadas ações com metodologias específicas para cada um dos públicos, docentes e discentes. Parte da equipe do PAESA ficou responsável pela oficina de docentes e parte da equipe responsável pela oficina de discentes. As temáticas apresentadas para ambos os públicos, de forma adaptada para cada um deles, foram: água no Brasil e no mundo, águas superficiais e sua importância, águas subterrâneas e aquíferos, e saúde ambiental (Figura 2).

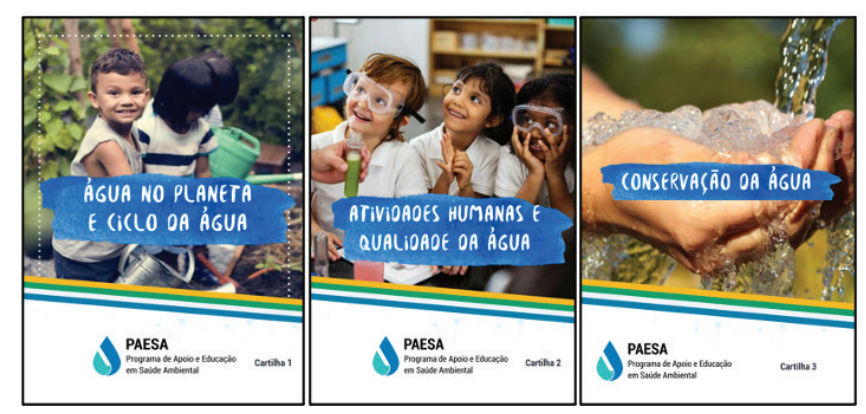

Figura 2. Material didático elaborado para o projeto

Foi realizado inicialmente um diagnóstico rápido participativo (DRP) para docentes e discentes, com o propósito de identificar as percepções sobre o ambiente em que vivem. A partir das percepções, trabalhou-se o conteúdo proposto, além de obter importantes informações sobre o reconhecimento do espaço em que se vive para extrair destas informações estratégias de construção de conhecimento. Após o DRP, tanto docentes como discentes realizaram dinâmica da casa dos sonhos: como é o ambiente em que gostaria de viver (ambientalmente saudável) e o que falta para conquistá-lo? Quais estratégias podem ser idealizadas e realizadas? Qual o papel de cada um para a construção do ambiente imaginado? Além disso, os docentes trabalharam com visita a campo, em ambientes que representam prejuízo à saúde ambiental, para produção de vídeo, como construção de objetos de aprendizagem. Os discentes trabalharam sobre qualidade da água com utilização de ECOKITS como laboratório de análise da água.

Na segunda campanha realizada de modo presencial no município, também com adequações de conteúdo para docentes e discentes, os seguintes conteúdos foram apresentados: atividades humanas que impactam a natureza, contaminantes que poluem a água, efeitos da poluição e da contaminação da água e doenças transmitidas pela água. Os discentes participaram da roda de história "Vic e Moleco" (Figura 3), livro construído a partir dos personagens criados para o PAESA, no qual participavam da elaboração de um final para a história. 


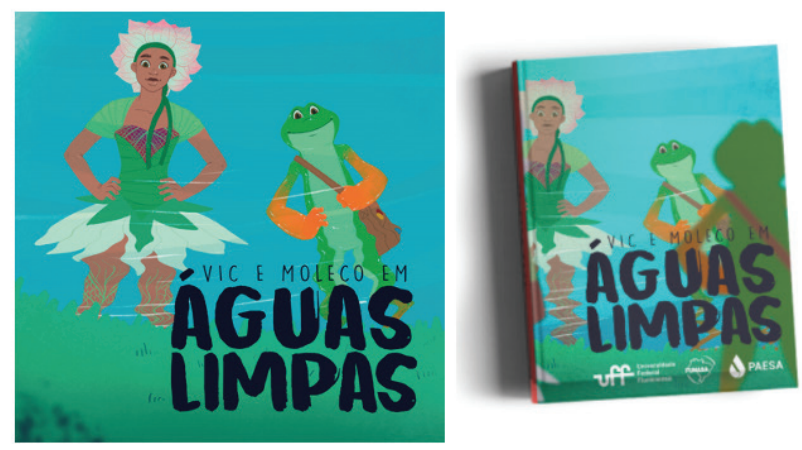

Figura 3. Livro construído a partir dos personagens criados para o PAESA, no qual participavam da elaboração de um final para a história.

Os discentes e docentes construíram spots de rádio como objetos de aprendizagem. Os docentes construíram, desenvolveram planos de aula e de estratégias para tornar a escola ambientalmente saudável, bem como boas práticas ambientais contínuas.

Na terceira campanha realizada de modo presencial no município, foi realizada uma devolutiva para docentes e discentes do diagnóstico da qualidade da água das escolas avaliadas e oficina sobre conservação da água, águas residuais, medidas remediadoras para qualidade da água a partir de tecnologias de baixo custo e orientação de tecnologias que podem ser requisitadas aos órgãos competentes para a solução da baixa qualidade da água nos municípios amapaenses. As oficinas trabalharam sobre o engajamento da comunidade na busca de soluções possíveis para os problemas ambientais enfrentados no município. Foi trabalhado arduamente sobre a importância da mudança de hábitos que vêm da cultura e da distinção entre homem e natureza firmada na nossa evolução como espécie.

\section{Comunidade de Aprendizagem em Saúde Ambiental - CASA}

O programa PAESA criou a CASA para formação continuada e à distância, que se destina aos docentes do ensino básico das escolas públicas no Estado do Amapá. O objetivo da CASA foi criar um espaço de interação, colaboração e compartilhamento com os docentes que participaram da formação, além de ser um repositório de materiais desenvolvidos no programa. O tema principal da plataforma foi a qualidade da água e a saúde ambiental.

Os docentes passaram por capacitação sobre educação a distância, ambiente virtual de aprendizagem, CASA e objetos de aprendizagem relacionados aos temas do programa. As oficinas realizadas tiveram por finalidade sensibilizar os professores da educação básica (ensino fundamental e médio) das escolas públicas do Estado do Amapá, ao uso do ambiente virtual do programa e, também, à pesquisa de repositórios para trazer novas metodologias de trabalho para a sala de aula na discussão da temática. Um outro fator a ser destacado é que a CASA teve o cuidado de desenvolver, em conjunto com docentes e discentes, materiais contextualizados com a realidade local de cada município, o que foi um grande diferencial.

\section{Educação Ambiental para Povos e Comunidades Tradicionais}

O eixo de atuação do PCT no PAESA teve por objetivo o apoio socioeducativo desse povo tradicional e a elaboração de estudo socioambiental estratégico das comunidades para estruturar oficinas para discutir sobre a qualidade da água nos municípios do Amapá que possuem atuação da FUNASA.

A temática da qualidade da água e a saúde ambiental foram os elementos centrais abordados nas oficinas de educação ambiental no PCT, cujo foco foi a melhoria da saúde ambiental nas zonas rurais. Portanto, para o desenvolvimento do mapeamento socioambiental, foi empreendido uma visão integrada que facilitasse os processos participativos e compartilhados. O resultado da produção de materiais pelos e para o PCT foi imprescindível. Não obstante, foi uma ação imbuída em expressar a percepção dos comunitários sobre a importância e o uso deste recurso natural em suas vidas, ao mesmo tempo para favorecer boas práticas de consumo, além do desenvolvimento de formas equilibradas de manejo do ambiente.

As oficinas realizadas com PCT tiveram por objetivos principais a sensibilização, problematização, indução a reflexão crítica dos comunitários para a temática da água e à saúde ambiental nas suas localidades. O mapeamento socioambiental realizado com PCT teve por finalidade a apresentação dos grupos locais quanto às suas realidades e a relação estabelecida com a água, nas quais importam os discursos e percepções sociais. Na finalização do programa foi construído o "Caderno das Águas", um material de caráter participativo, de autoria comunitária para os próprios comunitários, haja vista serem conhecedores de suas realidades, bem como detentores de representações que revelam objetivos, desejos e interesses associados aos recursos hídricos.

O resultado das atividades realizadas com PCT foi o reconhecimento de um grupo social como atores ativos na execução de políticas públicas que facultam o empoderamento socioambiental (territorial) e a construção de saberes compartilhados e, também, proporciona processos mais sinérgicos na evolução das ações de saúde ambiental que resultem na autonomia de uso, frente às adversidades ambientais (contaminações e doenças) e a insuficiência da assistência plena do Estado. 
Os PCT do Amapá que foram escolhidos para participarem do PAESA seguiram os seguintes critérios: saneamento precário, conflitos socioambientais, pobreza, escola ativa na comunidade e logística. As atividades foram distribuídas em três campanhas de campo, sendo que na primeira foram realizadas oficinas de educação ambiental e mapeamento socioambiental, do qual foi desenvolvido um vídeo socioambiental de cada comunidade contendo importantes entrevistas com comunitários; na segunda campanha foi realizada a produção de materiais para a comunidade tais como: produção de mapas falados que resultou na produção do Caderno das Águas e nos spots de rádio; na terceira campanha foi realizada a devolutiva para as comunidades do diagnóstico da qualidade das águas das comunidades avaliadas, oficina sobre conservação da água, águas residuais, medidas remediadoras para qualidade da água a partir de tecnologias de baixo custo e orientação de tecnologias que podem ser requisitadas aos órgãos competentes para a solução da baixa qualidade da água nos municípios amapaenses. Nas oficinas foi trabalhado o reconhecimento do papel ativo que a comunidade pode ter na busca de soluções possíveis para os problemas ambientais enfrentados no município.

\section{RESULTADOS E DISCUSSÃO}

Refletir sobre a educação ambiental é fundamental para o desenvolvimento de práticas construtivas que possam ser 0 alicerce de uma sociedade ambientalmente saudável e sustentável. O termo educação ambiental, comumente utilizado, necessita ser bem compreendido, para que se possa, de fato, cumprir o seu papel na formação de uma sociedade que estabeleça uma relação harmônica e respeitosa com o meio ambiente. Há inúmeras definições para o ato de educar, tais como, instruir, informar, disciplinar, doutrinar, ou mesmo, em visões não tradicionais de educação, podemos pensar em emancipar-se, elaborar ou construir conhecimento. Em todas as definições, por mais que sejam diferentes em suas abordagens metodológicas, não o são em sua essência.

Nas duas situações, a prática educacional ambiental acaba sempre sendo, essencialmente, informativa e não formativa. A ideia central é a de passar informação, conhecimento, conscientizar a população sobre as questões ambientais, como se isso bastasse para se construir boas práticas para com o meio ambiente, sendo que o que está em jogo é a construção de hábitos socialmente e culturalmente instituídos. Há uma ideia de transparência e linearidade do conhecimento e de autonomia dos indivíduos como se estes fossem capazes de mudar seus hábitos, instantaneamente, a partir da informação que recebem. Por exemplo, o Ministério da Saúde alerta que fumar é prejudicial à saúde e será mesmo que muitos indivíduos pararam de fumar, unicamente, a partir desta informação? A informação é importantíssima, mas temos que ir além.
É preciso refletir sobre o que significa construção de conhecimento e formação de consciência no âmbito da aprendizagem, especialmente, quando, o que se está em cena, é atitude e comportamento humano para com o ambiente. 0 agir sobre o ambiente implica hábitos e comportamentos automatizados. Reconhecer isto é fundamental, requerendo compreensão sobre o que são hábitos e como eles se desenvolvem e se instituem no comportamento humano, e desta forma, poder oferecer práticas educativas eficazes.

Para abordar esta temática, alçamos conhecimentos da neurociência cognitiva. A compreensão de como o cérebro e a mente funcionam na aprendizagem e a construção do conhecimento é importante para a busca de metodologias eficazes, principalmente quando o assunto implica hábitos e comportamento (Júnio; Barbosa, 2017). O cérebro humano é composto por uma arquitetura composta de bilhões de neurônios que trabalham em rede de forma altamente coordenada. A sua base funcional e estrutural relaciona-se diretamente à capacidade de memória. Há vários tipos de memória: de curto prazo, de longo prazo, procedural (automática), declarativa (refletida), podendo esta ser episódica (histórica) e semântica (dados aprendidos diante informação). Todos os tipos de memória, em conjunto, propiciam os diferentes tipos de conhecimento. Há conhecimentos implícitos e explícitos (memória implícita e explícita). Há ações (comportamentos) conscientes e não conscientes (automáticas) (Sargiani; Maluf, 2018).

Para exemplificar, vamos pensar na ação de andar. É possível descrever esta ação, trazer para a consciência e refletir o que é preciso fazer para andar, quais músculos do corpo são utilizados, o desequilíbrio de cinquenta por cento do corpo para apoio unilateral seguido de alternância etc. Mas a ação é executada sem esta consciência. É uma ação não consciente (automática). O conhecimento é procedural. 0 cérebro aprende, desenvolve um padrão de andar e executa de forma automática. Assim como a maioria das ações humanas se tornam automáticas, como falar, respirar, dirigir. As reações emocionais são comportamentos aprendidos, automatizados e os hábitos também o são. Para a construção do automatismo, o cérebro aprende e "enrijece" (sistematiza) esse aprendizado, se tornando de difícil modificação. Por isso, mudar hábitos não é algo simples que se modifica apenas em contato com uma nova informação. A mudança de hábito implica em emoção, construção de valores, espelhamento e repetição de rotina.

O comportamento humano é automatizado a partir de inúmeros hábitos. Os hábitos são moldados por diversas circunstâncias, uma delas, pela cultura a qual se pertence. Aqui vale um retorno à história do homo sapiens. Qual a relação primordial do homem com a natureza? Ao longo da história, o homem trilhou por um caminho de ruptura com a natureza. De uma unicidade entre homem/natureza, desen- 
volveu-se uma bipartição configurada por homem $x$ natureza. De um somatório de um, homem/natureza, passou-se a um somatório de dois, homem e natureza. À medida que o ser humano começou a desenvolver suas ferramentas e a desenvolver a sua sapiência (mente), ele foi agindo sobre o ambiente, conquistando cada vez mais distanciamento em seu elo com a natureza. Um distanciamento que surgiu da crença de um ser vivo superior capaz de moldar e modificar a natureza de acordo com as suas necessidades.

As diversas revoluções que os homo sapiens passaram ao longo da história, sendo cognitiva, científica e tecnológica (Harari, 2015), propiciaram uma capacidade de agir sobre a natureza, que passou a ser apenas um instrumento de desenvolvimento. Como a natureza passou a ser algo a parte, diferenciado do homem, estabeleceu-se a crença de não precisar cuidar da natureza como de si próprio. A valorização da natureza foi, ao longo da história, suplantada pela ideia de uso de seus recursos para o desenvolvimento e construção das sociedades tal como ela é hoje. No entanto, como os recursos são finitos, a natureza começou a reclamar, alardear o seu sufocamento e princípio de escassez. O homem, historicamente, diferenciado e bipartido da natureza (como se isso fosse possível) construiu uma relação de exploração e uso e, com isso, se tornou difícil de entender e modificar o seu comportamento. Há crenças e hábitos que controlam o seu comportamento há milênios e isso não muda a partir de uma simples informação. É necessária uma nova modelagem cultural sobre as práticas ambientais.

Retomando ao funcionamento do cérebro, temos a memória declarativa (aquela que podemos falar sobre; declarar que está na minha consciência, conteúdo aprendido). Mas há a memória implícita, que está latente e aparece nos hábitos, no comportamento. E ainda temos a memória prospectiva, que vai ao futuro imaginado, que vamos referir depois. Mas conhecimento/memória declarativa e conhecimento implícito/procedural é algo fundamental de compreender se o tema a ser trabalhado for educação ambiental.

O conhecimento declarativo em saúde ambiental pode ser acessado por meio de palestras, aulas, livros e diversas outras fontes de informações como, por exemplo, como a água contaminada prejudica a saúde, como jogar lixo na natureza é prejudicial, como fumar causa doenças e tantos outros tópicos que podem ser declarados ou informados. Mas há quem, mesmo com tanta informação disponível, continua poluindo as águas, jogando lixo na natureza e fumando? Por que isso acontece?

Saber sobre não implica mudança de hábito, de comportamento, de agir humano. Há um outro tipo de conhecimento, o conhecimento implícito/prático, que é programado e estabelecido em outra área do cérebro, diferente da área de memória declarativa. O cérebro aprende fazendo, registran- do na memória implícita e torna as ações, atividades automáticas. Da mesma forma, se consolida qualquer hábito e o comportamento, tais como: jogar lixo no chão, fumar, comer abusivamente etc.

Dall'Agnol (2019) refere sobre os diferentes tipos de memória em modos diferentes de saber, o saber-como e o saber-que. utiliza o seguinte exemplo:

uma pessoa pode saber-que é necessário nadar até a margem do rio para salvar-se do barco que está afundando, mas não saber-como agir. Não importa quantas informações teóricas ouça ali no momento crucial; se ela não aprendeu a nadar exercitando certas atividades até adquirir certas habilidades, ela não será capaz de salvar-se. Este último tipo de saber é adquirido por um processo de aprendizagem baseado no treinamento até resultar em saber prático e não meramente em apreender informações (p. 6).

Para o autor, o saber-que (conhecimento informacional/ teórico) pode até ser condição necessária do saber-como, mas certamente não é suficiente. As atividades práticas pressupõem de informações, declarativas ou observadas do ambiente para, mediante a prática, tornar-se memorizada, automatizada. Por exemplo, tocar piano, jogar xadrez, dirigir ou jogar lixo no rio e desperdiçar água são ações que se tornam habituais.

Desta forma, ao trazer os fundamentos da neurociência, torna possível iniciar a reflexão de que a educação ambiental, como possibilidade de instruir e informar ou construir e elaborar conhecimento não é, na maioria das vezes, uma estratégia que, por si só, propicie mudança de comportamento, de valores, de atitudes e de hábitos. Além de reconhecer o estabelecimento de conexões neuronais nos diferentes tipos de saberes, é preciso pensar que há o enraizamento cultural dos hábitos. A cultura molda as conexões neuronais do cérebro humano que não são simples de serem desfeitas. A costura cultural, neural e comportamental vai além de um simples alinhavo que se solta facilmente. Por isso precisamos discutir educação ambiental da forma como é empregada atualmente. Fazer uma palestra de como é importante parar de poluir o rio, de quantas doenças de veiculação hídrica existem, pode não ser, por si só, eficaz para a mudança de comportamento que precisamos para a construção de uma sociedade ambientalmente saudável e sustentável.

A educação ambiental necessita ir além. É uma informação fundamental, mas é, igualmente importante, colocar a percepção da comunidade no centro da discussão e elaborar estratégias de ações práticas permanentes na comunidade e nas escolas que possam propiciar verdadeiras mudanças de 
hábitos do comportamento humano para com o ambiente. Foi exatamente esta ideia que desenvolvemos na estrutura de implementação do PAESA e é com esta experiência que refletimos, após o término do projeto, se não seria mais producente a denominação de "prática ambiental" ao invés de "educação ambiental" para marcar uma mudança de paradigma que inclua a prática, a continuidade, o envolvimento da comunidade, para além da atuação apenas informativa do que, comumente, se propõe a educação ambiental do país. Mas isso é assunto para tantas outras discussões. A nossa intenção é apenas iniciar o debate.

O PAESA possibilitou a vivência de campo e uma experiência única de ouvir a percepção de quem está exposto diretamente aos prejuízos ambientais que comprometem a saúde. Na região do Amapá, a amplitude do saneamento básico tanto na zona urbana como rural é precária. A Companhia de Água e Esgoto do Amapá (CAESA) não consegue abastecer com a total eficácia o que a população necessita e grande parte do abastecimento fica por conta do poço amazonas e artesiano, quando é o caso. A qualidade da água é precária e há grande presença de doenças de veiculação hídrica. A primeira aprendizagem com a região é a bravura de um povo que resiste à escassez de tantas coisas e, ainda assim, sobrevive com grande entusiasmo pela vida. Não era incomum os olhos atentos de crianças de mais ou menos dez ou doze anos de idade prestando atenção a cada imagem e ouvindo cada fala, perguntando e querendo entender o ambiente em que vivem:

\begin{abstract}
“Mas se eu fizer a minha parte a água do rio vai ficar limpa? E se as outras pessoas não fizerem o mesmo? Vai sujar de novo". "A minha avó disse que ela sempre bebeu água do rio e nunca fez mal, então não vai fazer pra mim também". "A água vai acabar quando? Não vai dar para buscar lá no rio?" "Poxa minha mãe precisava escutar isso." "Lá em casa tem um vizinho que não gosta de usar banheiro, ele prefere ir perto do rio mesmo". "Esse tanto de lixo, não vai conseguir nunca sair daí". " Muito difícil ficar escolhendo cor de lixeira para jogar lixo, eu nem gravo que cor é o quê" (fragmentos de fala de alunos das escolas do Amapá do Projeto PAESA).
\end{abstract}

Por um lado, os discursos dos discentes são carregados de cultura e de costumes populares. Modificar costumes enraizados pela cultura não é nada fácil e os avanços são lentos. Por outro lado, o interesse dos jovens pelo compartilhamento de informações aponta para a possibilidade de desenvolver com eles uma nova realidade ambiental, para que eles causem algum efeito de mudança nos mais velhos e se solidifiquem para criar uma modificação de hábitos e costumes para as próximas gerações.
A ideia é aculturar a humanidade a partir das novas gerações. Por isso a importância da educação e do compromisso que buscamos com as redes de ensino do Amapá em tornarem-se escolas produtoras de "boas práticas" cotidianas para consolidar novas aprendizagens sobre saúde e ambiente de forma sustentável e eficaz. É a grande aposta do que foi realizado com o PAESA: Construir mais "Prática Ambiental", uma outra forma de entender a "Educação Ambiental".

\section{CONCLUSÃO}

Entre as ações de saneamento básico está: o abastecimento de água, o acesso a rede coletora, o tratamento de esgoto, o acesso a coleta, a destinação de resíduos sólidos e a drenagem de águas pluviais. A ausência de tais serviços tem resultado em precárias condições de saúde e incidência de doenças, principalmente de veiculação hídrica. Essa é uma situação muito comum nas regiões visitadas pelo PAESA nos municípios do Amapá.

Para além do saneamento básico, há o saneamento ambiental, que representa o conjunto de ações socioeconômicas que tem por objetivo alcançar a saúde ambiental, ou seja, um ambiente capaz de prevenir a ocorrência de doenças veiculadas pelo ambiente e de promover condições favoráveis à saúde da população urbana e rural. O saneamento básico se preocupa mais com o acesso ao serviço e o saneamento ambiental, além do acesso aos serviços de saneamento, que incluem as questões ambientais e de preservação do ambiente, incluindo a educação ambiental. Nesta concepção, a área de atuação do saneamento envolve, além das obras e das tecnologias implantadas, um processo educativo complexo que deve transformar indivíduos capazes de modificar seu entorno.

A disponibilização dos serviços de saneamento não garante benefícios efetivos às comunidades. Nem sempre há uma efetiva apropriação social dos serviços de saneamento. É necessário que se construa uma percepção de saneamento como um bem coletivo e indispensável à manutenção da qualidade de vida humana e ambiental. Tal percepção precisa ser construída a partir de uma educação ambiental que consiga desenvolver-se nas coletividades, a criticidade necessária para identificar, analisar e julgar os fatores que influenciam suas vidas nas diversas dimensões de sustentabilidade com possibilidade de propor encaminhamentos e auxiliar na execução de ações que, em consonância com a demanda da realidade vivenciada, permitam o aumento da qualidade de vida e manutenção do ambiente saudável.

Desta forma, a questão da educação ambiental, ou seja, educação em saúde ambiental deve ocupar o centro em toda e qualquer discussão de saneamento ambiental. Toda a infraestrutura de saneamento é fundamental, mas sem edu- 
cação ambiental, ou seja, sem o que estamos defendendo como "prática ambiental", o saneamento não se torna sustentável. Isso foi a grande aposta do PAESA: começar a disseminar a importância de tornar os integrantes das comunidades (escolas, PCT etc.) um agente participante na busca por caminhos e estratégias que modifiquem as realidades locais.

\section{Agradecimentos}

Os autores agradecem a Fundação Nacional de Saúde (FUNASA) pela oportunidade de execução do projeto que representou uma experiência extremamente enriquecedora para todos os componentes do grupo e que se apresenta como um marco na democratização do conhecimento no estado no Amapá.

\section{REFERÊNCIAS}

Baptista Neto, J.A. et al. 2020. Sustainability and the academy. Revista S\&G 15, 2:91-92. https://doi.org/10.20985/19805160.2020.v15n2.1667

Carvalho, A.I. 1978. Saúde e educação de base: algumas notas. Saúde em Debate 7/8: 61-65.

Dall'Agnol, D. 2019. Saber moral: fundamentos epistêmicos da neurobioética. Filosofia Unisinos 20, 1:65-75. https://doi. org/10.4013/fsu.2019.201.08
Duhigg, C. 2012. O poder do hábito: por que fazemos o que fazemos na vida e nos negócios. Editora Objetiva.

Freire, P. 1979. Educação e Mudança. Rio de Janeiro: Paz e Terra.

Harari, Y.N. 2015. Sapiens: uma breve história da humanidade. L\&PM.

Júnio, C.O.S.; Barbosa, I.S. 2017 Neurociência cognitiva e educação infantil: possibilidades de aprendizado. Boletim Informativo Unimotrisaúde em Sociogerontologia 8, 2:49-59.

Mello, G. 1975. Observações da interação professor-aluno: uma revisão crítica. Cadernos de Pesquisa, 12:19-27.

Sargiani, R. D. A., \& Maluf, M. R. 2018. Linguagem, Cognição e Educação Infantil: Contribuições da Psicologia Cognitiva e das Neurociências. Psicologia Escolar e Educacional, 22(3):477484.

Schall, V.T. 1994. Environmental and Health Education for School-Age Children: A Transdisciplinary Approach. Cadernos de Saúde Pública 10, 2: 259-263. https://doi.org/10.1590/ S0102-311X1994000200013

Tatochenco, V. 1979. Educação Sanitária. A Saúde no Mundo, 32:24-28.

World Health Organization. 1985. The Control of Schistosomiasis: report of a WHO expert committee [meeting held in Geneva from 8 to 13 November 1984]. Geneva: WHO.

Recebido: 03 nov. 2020

Aprovado: 03 nov. 2020

DOI: 10.20985/1980-5160.2020.v15n3.1688

Como citar: Pompermayer, F.C.L.; Fernandes, J.; Shenkel, M.H. et al. (2020). Programa de Apoio e Educação em Saúde Ambiental no estado do Amapá: a busca por uma educação ambiental que contribua para a construção de uma sociedade ambientalmente saudável e sustentável. Revista S\&G 15, 3, 314-321. https://revistasg.emnuvens. com.br/sg/article/view/1688 